\title{
Heavy Crude Oil Upgrading: Jazmin Crude
}

\author{
Jesús Alirio Carrillo*, Laura Milena Corredor \\ Ecopetrol S. A: Refining and Petrochemical, Instituto Colombiano del Petróleo, Bucaramanga, Colombia \\ Email: *jesusaliriocarrillo@yahoo.com
}

Received July 17, 2013; revised August 20, 2013; accepted August 27, 2013

Copyright (C) 2013 Jesús Alirio Carrillo, Laura Milena Corredor. This is an open access article distributed under the Creative Commons Attribution License, which permits unrestricted use, distribution, and reproduction in any medium, provided the original work is properly cited.

\begin{abstract}
The Jazmin crude oil is located at the heart of Middle Magdalena in Colombia. It is heavy and sour crude oil with 43 wt.\% of vacuum bottoms. It cannot be processed at the conventional refinery without being mixed with other lighter crudes, and should be upgraded to produce synthetic crude with higher concentration of distillates and lower acidity and carbon content. In this paper eight upgrading alternatives are presented. The alternatives include the processing of the crude, reduced crude and vacuum bottoms of the Jazmin crude oil using the following technologies: Distillation, solvent deasphalting, visbreaking, Delayed Coking, and Hydrotreating. The experiments were conducted at pilot scale, and there were used standard analysis techniques such as ASTM. In this study it was found that Jazmine crude oil and its heavy components produce high distillate yields when they were processed with thermal conversion processes. In addition those processes reduce the products acidity. Within the analyzed scheme the one corresponding to the visbreaking of the crude oil and the Delayed Coking of the vacuum bottoms from the visbreaking is perhaps the most attractive, giving 5.9 wt.\% of gas, 78.2 wt.\% of distillates and 15.9 wt.\% of coke.
\end{abstract}

Keywords: Jazmin Crude; Upgrading; Visbreaking; Deasphalting; Coking; Thermal Conversion; Heavy Crude; Acidity

\section{Introduction}

The depletion in reserves of light and medium crude oils has focused interest in heavy oils [1,2]. Furthermore, there is currently high demand for $20^{\circ}-25^{\circ}$ API quality crude oil because the production of Maya and other similar crude oils has been declining in recent years. Exports of Maya crude oil have decreased by about 1 million of barrels per day over the past seven years [3].

Crude oils located in the Middle Magdalena region of Colombia, such as Teca, Nare and Jazmín, are typically viscous and therefore require diluents for their transport by pipeline. They are considered as heavy crude oils. These crude oils do not have high concentrations of coke promoters, so they are sometimes mixed with a pool of crudes suitable for submission to a conventional refining process. However, they are characterized by high acidity (NN $>3.9 \mathrm{mg} \mathrm{KOH/g}$ of oil), which is a problem for transportation and refining. An important aspect of the implementation of the thermal processes to acid crudes is that they eliminates or substantially reduces its acidity [4, 5].

Heavy crude oils like Jazmin are cheaper and have lower profits per barrel than conventional oil. However,

"Corresponding author. their refining margin could be improved if they are properly handled. For such a purpose, the conventional processes are based on carbon rejection, hydrogen addition or processes with both technologies [6-12]. Carbon reject technologies includes processes such as visbreaking, thermal cracking and coking while hydrogen addition technologies are classified depending on the type of the reactor used.

In the group of carbon reject technologies, delayed coking and fluid-bed coking continue to be the major process route for producing distillates from vacuum bottoms [13]. Delayed coking (DC) is a thermal process which converts vacuum residue or other residue feedstocks into gas, light products and petroleum coke. DC distillates have a large proportion of olefins which under conditions of temperature, residence time and pollutants tend to polymerize forming gums and degrade their quality. To control these reactions, the DC liquid effluents should undergo hydrotreating processes which stabilize them by the saturation of their double bonds. The coke production ranges from 18 to $30 \mathrm{wt} . \%$ of the residual oil, depending on the composition of the feedstock and the operating conditions.

Fluid-bed coking is a continuous process where petroleum coke is combusted to provide process heat, avoid- 
ing the used of fuel or natural gas as used in DC. With fluid-bed coking results three are lower coke yields, higher liquid and gas production than with DC.

Visbreaking (VBR) is probably the lowest cost conversion technology. It is a thermal cracking process at low temperatures to reduce the viscosity of the feedstock and produces gases, naphtha and fuel oil and in some cases gas oils which can be used as feedstock for Fluid Catalytic Cracking (FCC). Usually the VBR feedstock is constituted by vacuum bottoms with CCR of $20 \mathrm{wt} . \%$ but in some cases it consists of pitch with CCR of $40 \mathrm{wt} . \%$.

Solvent deasphalting process (SDP) is still having high importance in the world [14-16]. SDP is a physical separation process by means of a solvent. Its products are deasphalted oil (DAO) and pitch or deasphalting bottoms (DAB) rich in aromatics with high concentration of impurities such as metals ( $\mathrm{Ni}, \mathrm{V}$ ), sulfur, asphaltenes and Conradson carbon. The DAO can either be used for the production of lube oil and paraffinic waxes or as feedstock for the FCC process or for the hydrocracking. The $\mathrm{DAB}$ is used either to prepare asphalt or as feed to the visbreaking process. Pitches like DAB had been generally expected to have processing problems in the delayed Coker as unstable feeds due to the concentrated asphaltenes and double bonds.

Foster Wheeler had patented the integration of SDA and DC and claimed that there was a synergistic benefit from combining these two technologies that produced a lower coke yield. The technology is marketed by Foster Wheeler as the ASCOTSM process [16]. The effort to improve these processes continues as it is shown in the works of Bjoror O. for the precipitation of asphaltenes from Athabasca bitumen using $\alpha, \alpha, \alpha$-trifluorotoluene [17].

\section{State of the Art}

Heavy crude oils are the alternative to supply refineries in the world. At present heavy crudes of the Orinoco and those from Canadian tar sands undergo upgrading processes to produce synthetic crude oils, which are already commercialized [18]. The main problem for upgrading heavy crude oils is their high concentration of carbon within the vacuum bottoms, however, the heavy crude oil from the Middle Magdalena despite being viscous have low levels of coke promoters (Vacuum bottoms with CCR 17.9 wt.\%, and insoluble in $\mathrm{n}^{-} \mathrm{C}_{7} 4.6$ wt.\%), which made them suitable for either a process of Delayed Coking (DC) or hydrotreatment (HDT). Thermal processes break down the molecules that cause acidity [17], so the distillates of a Delayed Coking technology should present low values of $\mathrm{NN}$, compared with the same of the original oil.

For crude oil vacuum bottoms handling, the processing facilities installed at the conventional refinery allow the production of asphalts for the pavement of the roads as well as the production of fuel oil, diluting the vacuum bottoms with appropriate solvents or by vacuum bottoms visbreaking. However, the fuel oil consumption in the world is going down and the refinery should be located near shore to facilitate it shipping.

For the upgrading of these crudes different technologies are combined such as fractionation, SDP, thermal cracking (DC and VBR), and HDT mainly. As a result of the application of these technologies, relatively light crudes with low levels of vacuum bottoms, high concentrations of middle distillates and stable diesel, and low sulfur concentrations, low NN, and low nitrogen concentration are obtained. These characteristics allow their use as part of the pool of crudes to a refinery and thus increase middle distillates yields such as diesel and Jet.

\section{Experimental}

For the upgrading of Jazmin crude oil, operational schemes that combine commercial technologies, using as raw material either crude oil or reduced crude or vacuum bottoms were studied. These cuts were obtained by Jazmin crude oil ASTM distillation. The distillation yields and the properties of the Jazmin crude oil are given in the Table 1, column 2. The yields of refined cuts are: atmospheric distillates $19.6 \mathrm{wt} \%$, and vacuum distillates 35.1 wt.\%, so the amount of vacuum bottoms are 45.3 wt.\%.

The runs were carried out at pilot plants designed and built in ECOPETROL-ICP [19-22]. The analyses were performed following ASTM methods in the laboratories of ECOPETROL-ICP, certified by ISO 9001.

The operating conditions used in the pilot plants were:

1) For Delayed Coking: load $2000 \mathrm{~g}$, temperature $510^{\circ} \mathrm{C}$, pressure 10 psig and run time of $2 \mathrm{~h}$.

2) For Visbreaking: temperature $480^{\circ} \mathrm{C}$ and residence time 60 seconds.

3) For Solvent Deasphalting: Solvent/Feed ratio was $6 / 1 \mathrm{vol} / \mathrm{vol}$, the bottom temperature $60^{\circ} \mathrm{C}$ and the top temperature $100^{\circ} \mathrm{C}$. The solvent used for deasphalting was $\mathrm{nC}_{4}$.

The analyzed operational schemes for the upgrading of the Jazmin crude oil were:

1) Processing of the crude:

a) Visbreaking (VBR) of the crude and Delayed Coking (DC) of the Visbreaked vacuum bottoms.

b) $\mathrm{nC}_{4}$ Crude Deasphalting and $\mathrm{DC}$ of its Demetallized oil (DMO), and

c) $\mathrm{nC}_{4}$ Crude Deasphalting and $\mathrm{DC}$ of the bottoms from Deasphalting (DAB).

2) Processing of the reduced crude:

a) $\mathrm{nC}_{4}$ Solvent deasphalting of the reduced crude and DC of the bottoms from deasphalting, and

b) Delayed Coking of the reduced crude. 
Table 1. Alternatives for the upgrading of the crude Jazmín.

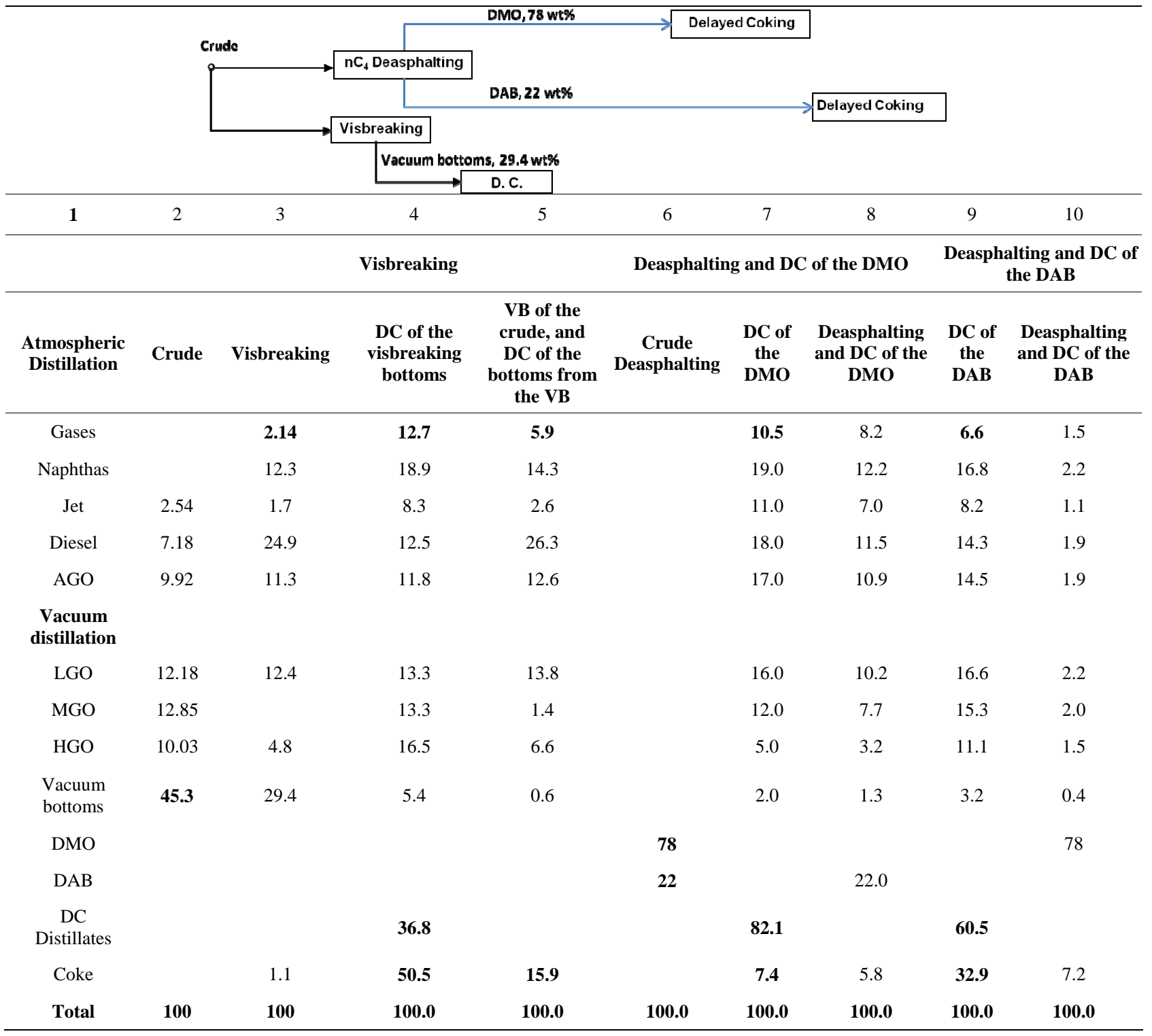

DC—Delayed Coking; VB_-Visbreaking; DMO—Demetallized Oil; DAB_Deasphalter bottoms.

3) Processing of the vacuum bottoms:

a) Delayed coking of the vacuum bottoms.

b) $\mathrm{nC}_{4}$ Deasphalting of the vacuum bottoms, and $\mathrm{DC}$ of the deasphalting bottoms.

c) Visbreaking of the vacuum bottoms.

\section{Results and Analysis}

\subsection{Processing of Crude Jazmín}

For the upgrading of the Jazmín crude the schemes presented in the Table 1 were considered:

\subsubsection{Visbreaking of the Crude and Delayed Coking of the Visbreaked Vacuum Bottoms}

In this scheme, the crude Jazmín is subjected to the vis- breaking process (column 3 of Table 1), and the visbreaked vacuum bottoms corresponding to $29.4 \mathrm{wt}$.\% of the crude oil are subjected to DC.

In the column 2 of Table $\mathbf{1}$ is shown the composition of Jazmín crude oil; column 3 shows the yields of visbreaked crude. It is clear that the achieved conversion in the visbreaking process of the crude is high as the vacuum bottoms are reduced from 45.3 wt.\% in the virgin crude to $29.4 \mathrm{wt} . \%$ in the visbreaked crude. That means a conversion of 35.1 wt.\%. Moreover, vacuum distillates are reduced from 35.1 wt.\% to 17.2 wt.\%. That means a conversion of $51 \mathrm{wt} . \%$. As a result of this conversion atmospheric distillates are increased from $19.6 \mathrm{wt} \%$ to 50.2 wt.\%.

In the fourth column Table $\mathbf{1}$ in bold are given the 
yields corresponding to the DC of the visbreaked vacuum bottoms, and in normal is given the simulated distillation of the DC distillates. Although the feedstock to the DC is a visbreaked product, the coke production is relatively low and corresponds to $50.5 \mathrm{wt} . \%$.

In the fifth column of Table $\mathbf{1}$ is given the composition of the synthetic crude corresponding to the studied scheme. The yield of diesel is quiet high, $26.3 \mathrm{wt} \%$, of which most is produced in the visbreaking. In addition, it was found that the vacuum bottoms from the visbreaked Jazmín crude have a relatively high conversion capacity in the DC process. The yield of coke regarding the visbreaked vacuum bottoms is $50.5 \mathrm{wt}$ \% and regarding the synthetic crude of the scheme is 15.9 wt.\% (columns 4 and 5).

This is a scheme that reduces the amount of diluents for the transport and it requires low investment in upgrading technology, because DC processes only 29.4 wt.\% of the crude oil. Both distillates (from the Visbreaking and from DC) are unstable and required treatment with hydrogen.

As reference for comparison in the first column of the Table 2 are given the properties of the vacuum bottoms from the virgin crude. The promoters of coke increases significantly in the visbreaked vacuum bottoms as follows: CCR goes from 17.9 wt.\% to 34.9 wt.\% (an increase of 95 wt.\%), and asphaltenes from the SARA analysis goes from 14.5 wt.\% to 19.4 wt.\% (Table 2). For this reason, the coke yield in the process of visbreaked vacuum bottoms DC is high, and reaches 50.5 wt.\%, a value that agrees with the rule of thumb on expected coke $(1.5 \times \mathrm{CCR}=52.4 \% \mathrm{~m})$.

Another important aspect of this scheme is the acidity reduction as it is shown in the case of the vacuum bottoms. In the crude oil vacuum bottoms NN was $3.93 \mathrm{mg}$ $\mathrm{KOH} / \mathrm{g}$ of oil, and in the visbreaked vacuum bottoms was $0.8 \mathrm{mg} \mathrm{KOH} / \mathrm{g}$ of oil. That result confirms that thermal processes reduce the acidity of the feedstock.

\subsection{2. $\mathrm{nC}_{4}$ Crude Deasphalting and Delayed Coking of the Demetallized Oil (DMO)}

The yields of $\mathrm{nC}_{4}$ crude oil Deasphalting are 78.0 wt.\% of DMO and 22.0 wt.\% of bottoms (DAB, Table 1, column 6). Within the same table, in the column 7 in bold the DC yields are given (gas: 10.5 wt.\%, distillates: 82.1 wt.\%, and coke: 7.4 wt.\%), which totalize 100\%. The others results correspond to the simulated distillation of the DC distillates, which also correspond to $100 \%$. Because the promoters of coke have been removed from the feed in the previous process of Deasphalting, coke production in the last process is only $7.4 \mathrm{wt} . \%$. The CCR in the feedstock to the DC process is $4.4 \mathrm{wt} . \%$ as can be seen from Table 2, so the amount of coke is 1.6 times de amount of CCR in the feedstock. The sum of Jet and Diesel is $23.8 \mathrm{wt} . \%$ and the yield of naphtha is $15.6 \mathrm{wt} . \%$.
Within the distillates, the yield of atmospheric distillates is 65 wt.\% and the yield of vacuum distillates is 33.0 wt.\%.

In the consolidate of the synthetic crude is shown a coke production of $5.8 \mathrm{wt}$ \% regarding to the original crude (column 8 of Table 1), which is a rather low value for the upgrading schemes, however, it should be taking in account the production of $22.0 \mathrm{wt}$ \% of bottoms from deasphalting (DAB), with which the bottoms yield gives a total of $27.8 \mathrm{wt} . \%$ respect to the crude oil. DC distillates should be processed in HDT for their stabilization.

This is a scheme of high production of naphtha and high-capacity of the upgrading.

\subsection{3. $\mathrm{nC}_{4}$ Crude Oil Deasphalting and Delayed Coking of the Bottoms from the Deasphalting} The yields from the DC of the deasphalting bottoms are presented in the column 9 of Table 1 and the composition of the consolidated synthetic crude is given in the column 10. Coke production in the DC of the deasphalting bottoms is $32.9 \mathrm{wt} \%$, which is a rather low value considering that the DC feed correspond to the bottoms from the Deasphalting, however, according to the rule of thumb, the expected coke yield is $1.5 *$ CCR in the feedstock, It means $30 \mathrm{wt} \%$.

In the consolidated scheme the coke yield is $7.2 \mathrm{wt} . \%$ and the main product is the DMO with a yield of $78 \mathrm{wt} \%$ (column 10).

This is the scheme that produces the less quantity of solids (coke or bottoms from the Deasphalting process). It is also a low investment process with an average conversion, providing feed to the FCC process. DC distillates require hydrotreating.

\subsection{Processing of the Reduced Jazmín Crude $370^{\circ} \mathrm{C}+$}

The reduced crude is 80.4 wt.\% of the whole crude. The analyzed schemes are (Table 3):

1) $\mathrm{nC}_{4}$ Solvent deasphalting of the reduced crude and DC of the bottoms from Deasphalting, and

2) Delayed Coking of the reduced crude.

The product quality of the studied schemes is presented in the Table 4.

\subsection{1. $\mathrm{nC}_{4}$ Solvent Deasphalting of the Reduced Crude and DC of the Deasphalter Bottoms}

In the column 2 of Table $\mathbf{3}$ in bold are given the yields of the Deasphalting process, and the others results correspond to the DMO composition. In the column 3 the composition of the bottoms from the Deasphalting process is given. In the column 4 the yields of the DC of the deasphalter bottoms are given. In the column 5 the composition of the synthetic crude is given.

Regarding reduced crude, the DMO yield is 69.5 wt.\% 
Table 2. Quality of the products from the upgrading of the crude Jazmín.

\begin{tabular}{|c|c|c|c|c|c|c|c|}
\hline & $\begin{array}{l}\text { Vacuum } \\
\text { Bottoms }\end{array}$ & $\begin{array}{l}\text { Visbreaked Vacuum } \\
\text { Bottoms }\end{array}$ & $\begin{array}{c}\text { DC of VBR vacuum } \\
\text { bottoms }\end{array}$ & DMO & DAB & $\begin{array}{l}\text { DC of } \\
\text { DMO }\end{array}$ & $\begin{array}{l}\text { DC of } \\
\text { DAB }\end{array}$ \\
\hline Density at $5^{\circ} \mathrm{C}, \mathrm{g} / \mathrm{cm}^{3}$ & 1.0262 & 1.0745 & 0.9395 & 0.9684 & 1.049 & 0.92 & 0.925 \\
\hline API & 6.3 & 0.1 & 19 & & 3.3 & & 21.3 \\
\hline CCR, wt.\% & 17.9 & 34.9 & 4.9 & 4.4 & 20 & 2.2 & 1.97 \\
\hline Sulphur, wt.\% & 1.7 & 2.1 & 1.6 & 1.5 & & 1.3 & 1.646 \\
\hline Ashes, wt.\% & - & 0.458 & & & & & \\
\hline Ca, ppm & 2666.0 & 1128 & & 54.4 & 1109 & & \\
\hline $\mathrm{Ni}, \mathrm{ppm}$ & 130.7 & 213 & & 17.379 & 214.88 & & \\
\hline V, ppm & 167.27 & 243 & & 15.684 & 280.7 & & \\
\hline $\mathrm{Na}, \mathrm{ppm}$ & 38.5 & 29 & & & & & \\
\hline $\mathrm{Ni}+\mathrm{V}, \mathrm{ppm}$ & 298.0 & 456 & & 33 & 496 & & \\
\hline Refractive index & & & & 1.5184 & & & \\
\hline $\mathrm{i}-\mathrm{nC}_{7}, \mathrm{wt} . \%$ & 4.6 & 25.7 & & & 16.25 & & \\
\hline i-nC , wt.\% & 11.3 & 32.3 & & & 36.07 & & \\
\hline Viscosity-1, cP & $30800 @ 100^{\circ} \mathrm{C}$ & $225000 @ 120^{\circ} \mathrm{C}$ & & 33 & & & \\
\hline Viscosity-2, cP & $4950 @ 120^{\circ} \mathrm{C}$ & $69500 @ 130^{\circ} \mathrm{C}$ & & $82 @ 80^{\circ} \mathrm{C}$ & & & \\
\hline Basic N, wt.\% & 0.284 & 0.4 & 0.2 & 0.124 & 0.389 & 0.11 & 0.18 \\
\hline Total N, ppm & 7451 & 1.2 & 6130 & 3679 & & & 5302 \\
\hline N.N, mg KOH/g & 3.93 & 0.8 & & & & & \\
\hline \multicolumn{8}{|l|}{ SARA analysis, wt.\% } \\
\hline S & 8.9 & 5.3 & & & & & \\
\hline A & 55.2 & 45.3 & & & & & \\
\hline $\mathrm{R}$ & 21.4 & 30.0 & & & & & \\
\hline A & 14.5 & 19.4 & & & & & \\
\hline
\end{tabular}

VBR—Visbreaked; DC—Delayed Coking; DMO—Demetallized Oil; DAB—Deasphalter bottoms.

and the deasphalting bottoms yields are 30.5 wt.\%. Within the DMO, 37 wt.\% are vacuum bottoms. This result corresponds to low concentration of CCR within the feedstock (11.2 wt.\%). Within de DAB, the main component correspond to the vacuum bottoms (75 wt.\%, column 3 of Table 3 ).

The Delayed Coking of the DAB produces 31.7 wt.\% of coke, which is a low value considering that the feed is deasphalter bottoms and this is due to the low concentration of coke promoters within the feed stock (CCR $=26.3$ wt.\%, Table 4) and to the fact that many of the components of the CCR are soluble in cyclohexane [23]. According to the rule of thumb, the expected coke is 39.45 wt.\%.

In the consolidated scheme (synthetic crude oil-column 5 of Table 3), coke production is only $7.8 \mathrm{wt} . \%$.
The main processes in this scheme are physical separations, and the conversion is very low and corresponds to the DC process. The upgrading costs in this scheme are low. This is because in the DC is processed only 21.2 wt.\% of the feedstock. The vacuum bottoms are reduced from 45.3 wt.\% to 21.5 wt.\%. That is a substantial reduction. DC distillates must be subjected to hydrotreating. The metals concentration within the DMO is normal for the FCC feedstock or for its Hydrocracking.

\subsubsection{Delayed Coking of Reduced Crude}

In the column 6 of Table 3 in bold are given the delayed Coking yields of the reduced crude, and the other results correspond to the composition of the DC distillated.

In this alternative the production of coke is very low (11.7 wt.\% with respect to the virgin crude-Table 3, 
Table 3. Alternatives for the upgrading of the Jazmín reduced crude oil.

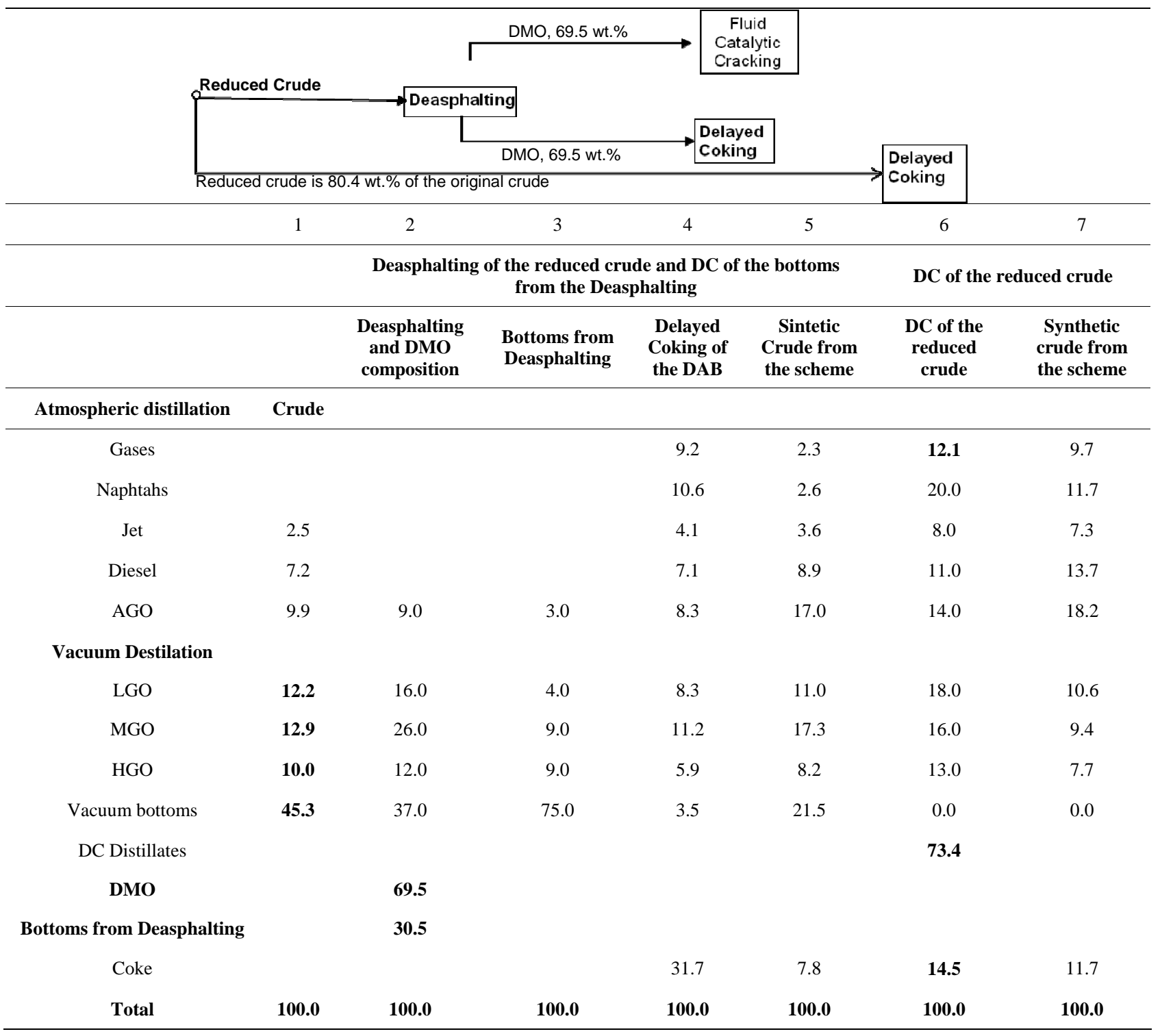

DC—Delayed Coking; DMO—demetalized Oil; DAB—Bottoms from Deasphalting.

column 7), and the conversion is high, especially to middle distillates (Jet + Diesel), which goes from $9.7 \mathrm{wt} . \%$ in the original oil to $21.0 \mathrm{wt}$ \% in the synthetic crude. The vacuum bottoms are totally converted. According to the rule of thumb, the expected coke was $1.5 *$ CCR within the feedstock, it means $16.8 \mathrm{wt} \%$, and the explanation for this behavior consist in the fact that many components of the CCR are soluble in cyclohexane [23].

This alternative produces high yields of atmospheric distillates; it is costly because it involves processing all reduced crude, which accounts 80.4 wt.\% of the whole crude. Distillates from DC must be subjected to hydrotreating.

When comparing the quality of the studied schemes products (Table 4), we observed expected behaviors. The
$\mathrm{Ni}+\mathrm{V}$ concentration within the DMO is $31.2 \mathrm{ppm}$, so we should consider it hydrotreating to adequate feed to catalytic cracking process.

\subsection{Processing of the Vacuum Bottoms from the Jazmin Crude Oil}

The analyzed schemes were (Table 5):

1) Delayed coking of the vacuum bottoms.

2) $\mathrm{nC}_{4}$ Deasphalting of the vacuum bottoms, and DC of the deasphalter bottoms.

3) Visbreaking of the vacuum bottoms.

In the column 3 of Table 5 in bold the main products of DC are shown: gas, distillates and coke, and the other results correspond to the simulated distillation of distil- 
Table 4. Quality of the products from the upgrading of reduced crude.

\begin{tabular}{|c|c|c|c|c|c|}
\hline & Reduced crude (RC) & DMO & DAB & DC of DAB & DC of RC \\
\hline Density@ $15^{\circ} \mathrm{C}, \mathrm{g} / \mathrm{cm}^{3}$ & 1.0086 & 0.9817 & 1.0608 & 0.9314 & 0.936 \\
\hline API & 8.7 & & 1.8 & 20.3 & 19.6 \\
\hline CCR, wt.\% & 11.2 & 4.7 & 26.3 & 2.99 & 3.6 \\
\hline Sulphur, wt.\% & 2.25 & 1.6 & 2.3 & 1.533 & 1.5 \\
\hline Ca, ppm & 345 & 41.5 & 1541 & & \\
\hline $\mathrm{Ni}, \mathrm{ppm}$ & 79 & 17.0 & 195.78 & & \\
\hline V, ppm & 93 & 14.2 & 253.25 & & \\
\hline Na, ppm & 69 & & & & \\
\hline $\mathrm{Ni}+\mathrm{V}, \mathrm{ppm}$ & & 31.2 & 449.0 & & \\
\hline Refractive Index & & 1.5269 & & & \\
\hline insolubles in $\mathrm{nC}_{7}$, wt.\% & 2.6 & & 11.8 & & \\
\hline insoluubles in $\mathrm{nC}_{5}$, wt.\% & 6.2 & & 23 & & \\
\hline Viscosity-1, cP & 577 a $120^{\circ} \mathrm{C}$ & 92 & & & \\
\hline Viscosity-2, cP & 79200 a $135^{\circ} \mathrm{C}$ & 270 & & & \\
\hline Basic N, wt.\% & 0.218 & 0.1 & 0.4 & 0.2 & 0.17 \\
\hline N Total, ppm & 6387 & 3828 & & 5414 & 5570 \\
\hline N. N, mg KOH/g & 7.4 & & & & \\
\hline Pour point, ${ }^{\circ} \mathrm{C}$ & 42 & & & & \\
\hline SARA analysis, wt $\%$ & & & \multicolumn{3}{|c|}{ DMO-Demetallized Oil } \\
\hline $\mathrm{S}$ & 18.5 & 34.9 & \multicolumn{2}{|c|}{ DAB-Bottoms from } & \\
\hline A & 54 & 51.1 & \multicolumn{2}{|c|}{ deasphalting } & \\
\hline $\mathrm{R}$ & 25.1 & 14 & \multicolumn{2}{|c|}{ DC-Delayed Coking } & \\
\hline A & 2.4 & & \multicolumn{2}{|c|}{ RC-Reduced crude } & \\
\hline
\end{tabular}

lates from DC. Column 4 shows the synthetic crude from this scheme before hydrotreating and column 5 the same products after Hydrotreating. Columns 6 to 9 present data from the scheme of vacuum bottoms deasphalting and DC of deasphalter bottoms. Column 9 shows the synthetic crude from this scheme.

Column 10 presents the data corresponding to the Visbreaking of the vacuum bottoms and column 11 shows the synthetic crude regarding to this scheme.

The composition of all synthetic crude is given considering not only the products of the given scheme of processing, but also include the components of oil which do not fall in the transformations given.

\subsubsection{Delayed Coking of the Vacuum Bottoms (Table 5)}

Coke production in relation to vacuum bottoms is of 22.2 wt.\% (column 3), which is a fairly low value for this type of feed. This is due to the low concentration of coke precursors. The insolubles in $n-C_{7}$ are completely soluble in cyclohexane [23]. The CCR in the vacuum bottoms is 17.9 wt.\%, and the insolubles in $\mathrm{n}-\mathrm{C}_{7}$ are $4.6 \mathrm{wt} \%$ (Table 6). The typical values of CCR in the vacuum bottoms are above 25 wt.\% (for the Castilla crude oil they are 37 wt.\%).

In the consolidated for crude oil, the coke production is only $10.1 \mathrm{wt} \%$, a value similar to the production of coke in the consolidated scheme of DC of reduced crude. In the synthetic crude the production of naphtha is 6.2 wt.\% and the yield of middle distillates (Jet and Diesel) is increased from 9.7 wt.\% to 16.8 wt.\% (column 5). Hydrogen treatments applied to DC distillates do not significantly alter their composition (columns 4 and 5 of Table 6).

This is a scheme of high conversion where only vacuum bottoms are processed; thereby the size of the up- 
Table 5. Vacuum bottoms upgrading alternatives.

\begin{tabular}{|c|c|c|c|c|c|c|c|c|c|c|}
\hline 1 & 2 & 3 & 4 & 5 & 6 & 7 & 8 & 9 & 10 & 11 \\
\hline & & \multicolumn{3}{|c|}{$\begin{array}{l}\text { Delayed Coking }(\mathrm{DC}) \text { of the } \\
\text { vacuum bottoms }\end{array}$} & \multicolumn{4}{|c|}{ Deasphalting of vacuum bottoms and DC of DAB } & \multicolumn{2}{|c|}{$\begin{array}{l}\text { Visbreaking (VR) of } \\
\text { the vacuum bottoms }\end{array}$} \\
\hline $\begin{array}{l}\text { Atmospheric } \\
\text { Distillation }\end{array}$ & $\begin{array}{c}\text { Crude } \\
\text { oil }\end{array}$ & DC & $\begin{array}{l}\text { Synthetic } \\
\text { crude }\end{array}$ & $\begin{array}{c}\text { Synthetic } \\
\text { crude + } \\
\text { HDT }\end{array}$ & Deas-phalting & DAB & $\begin{array}{l}\text { DC of } \\
\text { DAB }\end{array}$ & Consolidated & VR & $\begin{array}{l}\text { Synthetic } \\
\text { Crude }\end{array}$ \\
\hline Gases & & 9.9 & 4.5 & 4.5 & & & 9.5 & 2.8 & 2.0 & 0.9 \\
\hline Naphtha & & 20.0 & 6.2 & 5.5 & & & 19.0 & 3.1 & 5.7 & 2.6 \\
\hline Jet & 2.5 & 9.0 & 5.3 & 5.3 & 2.5 & & 8.0 & 3.9 & 0.9 & 2.9 \\
\hline Diesel & 7.2 & 12.0 & 10.9 & 11.5 & 7.2 & & 13.0 & 9.3 & 3.7 & 8.9 \\
\hline AGO & 9.9 & 12.0 & 13.6 & 13.9 & 9.9 & & 11.0 & 11.7 & 4.7 & 12.1 \\
\hline \multicolumn{11}{|l|}{$\begin{array}{l}\text { Vacuum } \\
\text { distillation }\end{array}$} \\
\hline LGO & 12.2 & 13.0 & 16.2 & 16.8 & 12.2 & & 14.0 & 14.5 & 3.5 & 13.8 \\
\hline MGO & 12.9 & 14.0 & 17.2 & 17.5 & 12.9 & 2.0 & 13.0 & 15.0 & 12.2 & 18.4 \\
\hline HGO & 10.0 & 20.0 & 16.2 & 15.0 & 10.0 & 10.0 & 14.0 & 12.3 & 15.7 & 17.1 \\
\hline $\begin{array}{l}\text { Vacuum } \\
\text { bottoms }\end{array}$ & 45.3 & & & & & 88.0 & 8.0 & 1.3 & 49.7 & 22.5 \\
\hline DMO & & & & & 36.0 & & & 16.3 & & \\
\hline $\mathrm{DAB}$ & & & & & 64.0 & & & & & \\
\hline DC distillates & & 67.9 & & & & & 57.0 & & & \\
\hline Coke & & 22.2 & 10.1 & 10.1 & & & 33.5 & 9.7 & 1.8 & 0.8 \\
\hline Total & 100 & 100 & 100.0 & 100.0 & 100.0 & 100.0 & 100.0 & 100.0 & 100.0 & 100.0 \\
\hline
\end{tabular}

DC—Delayed Coking; DAB_-Bottmos from Deasphalting; VR_-Visbreaking; HDT—Hydrotreating.

grader is reduced with respect to the processing of reduced crude.

\subsection{2. $\mathrm{nC}_{4}$ Deasphalting of the Vacuum Bottoms and DC of the Bottoms from the Deasphalter (Table 5)}

The DMO yield with respect to the vacuum bottoms is 36.0 wt.\% and the yield of deasphalter bottoms is 64.0 wt.\%. This low yield of DMO is an indicative of the high aromaticity of this type of vacuum bottoms, which is confirmed by the SARA analysis (Table 6), where the sum of aromatics + Resins + asphaltenes is $91.1 \mathrm{wt} \%$. This type of crude should not be processed in a low conversion scheme because the fuel oil production is quiet high. The deasphalter bottoms yield with respect to the crude oil is $29.0 \mathrm{wt}$ \% , a very high value.

Within the DC of the DAB are produced 9.5 wt.\% of gases, 57.0 wt.\% of distillates and 33.5 wt.\% of coke (Table 5, Column 8), and within the distillates $51.0 \mathrm{wt} . \%$ correspond to atmospheric distillates and $41.0 \mathrm{wt} \%$ to the vacuum distillates.
In the synthetic crude produced in this scheme (column 9), is observed that this scheme produces very low quantity of residues, only 9.7 wt.\%, but the DMO concentrates very high amount of metals (282 ppm, Table 6) and this is neither good for the FCC feedstock not for the Hydrocracking.

\subsubsection{Visbreaking of the Vacuum Bottoms (Table 5)} The Visbreaking of the vacuum bottoms produces a semi-synthetic crude oil in which the concentration of the cut corresponding to the vacuum bottoms is significantly reduced. It changes from $45.3 \mathrm{wt} \%$ in the original crude oil to 22.5 wt.\% in the semi-synthetic crude oil. On the other hand, the gas oils are increased from $45.0 \mathrm{wt} . \%$ in the raw material to $61.3 \mathrm{wt} . \%$ in the semi-synthetic crude (columns 2 and 11). The yield of coke is normal for this type of process.

The Visbreaking bottoms in the Table 6 correspond to liquid effluents from the Visbreaking process, excluding naphtha.

This scheme is an ideal arrangement for a low conver- 
Table 6. Properties of the products from the vacuum bottoms upgrading.

\begin{tabular}{|c|c|c|c|c|c|c|}
\hline & $\begin{array}{l}\text { Vacuum } \\
\text { Bottoms }\end{array}$ & $\begin{array}{c}\text { DC of vacuum } \\
\text { bottoms }\end{array}$ & DMO & DAB & $\begin{array}{l}\text { Visbreaking } \\
\text { bottoms }\end{array}$ & $\begin{array}{l}\text { Vacuum bottoms } \\
\text { from VBR }\end{array}$ \\
\hline 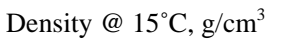 & 1.0262 & 0.9227 & 1.0284 & 1.0314 & 1.0459 & 1.0745 \\
\hline API & 6.3 & 21.8 & 6 & 5.6 & 3.7 & 0.1 \\
\hline CCR, wt.\% & 17.9 & 4 & 18.3 & 25.8 & 25.9 & 34.9 \\
\hline Sulphur, wt.\% & 1.73 & 1.64 & 2.0 & 2.1 & 2.1 & 2.1 \\
\hline Ca, ppm & 2666.0 & & 852.5 & 337 & 982 & 1128 \\
\hline $\mathrm{Ni}, \mathrm{ppm}$ & 130.7 & & 124.7 & 111.7 & 153 & 212.7 \\
\hline $\mathrm{V}, \mathrm{ppm}$ & 167.3 & & 157.8 & 158.6 & 200 & 242.8 \\
\hline $\mathrm{Na}, \mathrm{ppm}$ & 38.5 & & 33.2 & 43.5 & 32 & 29.4 \\
\hline $\mathrm{Ni}+\mathrm{V}, \mathrm{ppm}$ & 298 & & 282 & 270 & 354 & 455 \\
\hline i-nC 7 , wt.\% & 4.63 & & & 9.16 & 17.3 & 25.7 \\
\hline $\mathrm{i}-\mathrm{nC} \mathrm{C}_{5}, \mathrm{wt} \%$ & 11.27 & & & 21.43 & 20.9 & 32.3 \\
\hline Viscosity-1, cP & 30800 a $100^{\circ} \mathrm{C}$ & & $322000 @ 80^{\circ} \mathrm{C}$ & $4780 @ 120^{\circ} \mathrm{C}$ & & 0 \\
\hline Viscosity-2, cP & 4950 a $120^{\circ} \mathrm{C}$ & & $30100 @ 100^{\circ} \mathrm{C}$ & $1880 @ 140^{\circ} \mathrm{C}$ & & 225000 \\
\hline Básico N, wt.\% & 0.284 & 0.186 & 0.284 & 0.312 & 0.373 & 0.441 \\
\hline N Total, ppm & 7451 & 6681 & & & & 1.21 \\
\hline N.N, mg KOH/g & 3.93 & & & & 2.88 & 0.8 \\
\hline Pour point, ${ }^{\circ} \mathrm{C}$ & & & & & 51 & 126 \\
\hline Flash point, ${ }^{\circ} \mathrm{C}$ & & & & & 173 & 323 \\
\hline \multicolumn{7}{|l|}{ SARA analysis, wt.\% } \\
\hline S & 8.9 & & & & 15.1 & 5.3 \\
\hline A & 55.2 & & & & 45.3 & 45.3 \\
\hline $\mathrm{R}$ & 21.4 & & & & 22.7 & 30.0 \\
\hline A & 14.5 & & & & 12.4 & 19.4 \\
\hline
\end{tabular}

DC—Delayed Coking; DMO—Demetallized oil; VBR—Visbreaking.

sion refinery.

\section{Cost of Technologies for Evaluated Schemes}

The calculations were performed with the values presented in Table 7 and on the basis of 50.000 BOPD.

In the Table 8 are given the values of the different technological alternatives for the processing $50 \mathrm{KBOPD}$ of crude Jazmín. The lower cost alternative is the Visbreaking of the Vacuum, bottoms and Hydrotreating of the distillates obtained from the VBR, followed by the alternatives of Visbreaking of the crude and DC of the DAB.

\section{Conclusions}

1) Jazmin crude oil and its heavy components are sub- jected to thermal processes with excellent results due to the low concentration of coke promoters. Coke production in relation to vacuum bottoms is of $22.2 \mathrm{wt} . \%$, which is a fairly low value for this type of feed. This is due to the low concentration of coke precursors. The insolubles in $n-C_{7}$ are completely soluble in cyclohexane.

2) The scheme corresponding to the visbreaking of the crude oil and the DC of the vacuum bottoms from the visbreaking is perhaps the most attractive for its application because it has low capital cost and solves from the beginning the problem of crude acidity.

3) The best scheme to use depends on the needs of each refinery and its installed facilities.

4) Of the studied schemes, the less expensive because of the used technology is the Visbreaking of the vacuum bottoms, and Hydrotreating of the liquid effluents to stabilize all future products. 
Table 7. Technology costs.

\begin{tabular}{ccc}
\hline & $\begin{array}{c}\text { Value of the } \\
\text { technology }\end{array}$ & $\begin{array}{c}\text { Taken } \\
\text { value }\end{array}$ \\
\hline US\$/Bl & US\$/Bl \\
\hline Atmospheric Distillation & & 1000 \\
Atmospheric and Vacuum Distillation & $750-2200$ & 2000 \\
Deasphalting & $1850-8000$ & 4000 \\
Delayed Coking & $5800-12,000$ & 8000 \\
Hidrotreating & $3000-3500$ & 3000 \\
Visbreaking & $1800-3500$ & 3000 \\
Crude for the process, bl/day & & 50,000 \\
\hline
\end{tabular}

Table 8. Investment cost of the proposed schemes.

\begin{tabular}{|c|c|c|}
\hline & $\begin{array}{l}\text { Economic impact of the studied upgrading } \\
\text { alternatives of the Jazmin crude }\end{array}$ & MMUS\$ \\
\hline 1 & $\begin{array}{l}\text { Visbreaking (VR) of the vacuum bottoms and } \\
\text { HDT of the distillates from VR }\end{array}$ & 236 \\
\hline 2 & $\begin{array}{l}\text { Visbreaking of the crude and Delayed Coking of } \\
\text { the Visbreaked vacuum bottoms }\end{array}$ & 275 \\
\hline 3 & $\begin{array}{l}\text { Deasphalting of the crude } 199^{\circ} \mathrm{C}+\text { and } \mathrm{DC} \text { of the } \\
\text { bottoms obtained in the deasphalting. }\end{array}$ & 319 \\
\hline 4 & $\begin{array}{l}\text { DC of the Vacuum bottoms } \\
\text { and HDT of DC distillates }\end{array}$ & 327 \\
\hline 5 & $\begin{array}{l}\text { n-C4 Deasphalting of the vacuum bottoms; DC } \\
\text { of the DAB, and HDT of the distillates from DC }\end{array}$ & 331 \\
\hline 6 & $\begin{array}{l}\text { n-C4 Deasphalting of the reduced crude and DC } \\
\text { of the Deasphalted bottoms }\end{array}$ & 334 \\
\hline 7 & Delayed Coking of reduced crude & 478 \\
\hline 8 & $\begin{array}{l}\text { Deasphalting of crude } 199^{\circ} \mathrm{C}+ \\
\text { and DC of its DMO }\end{array}$ & 608 \\
\hline
\end{tabular}

5) Thermal upgrading schemes not only increase distillates yield and reject carbon, but also reduce the acidity of the products.

\section{REFERENCES}

[1] http://www.pacificrubiales.com/operations/colombia/prod uction.html

[2] http://www.pacificrubiales.com/operations/colombia/prod uction.html

[3] J. Plotkin, "Exploiting Unconventional Heavy Oils,” PTQQ1, 2007, pp. 65-67.

[4] M. Aldescu, "High-Quality Products from Sour Heavy Crudes,” PTQ Q3, 2012, pp. 115-120.

[5] J. A. Carrillo, L. G. Garzón, L. M. Corredor and H. J. Picon, "Visbreaking of Jazmin Crude Oil: Transport Alternatives," Preprints of Papers-American Chemical Society, Division of Fuel Chemistry, Vol. 52, No. 2, 2007, pp.

[6] M. G. Bienstock, et al., Patent USA 6086751, 2000.

[7] M. Aldescu, "Challenges of Heavy Crude Processing," Sour/Heavy, 2012, pp. 127-132. www.ptq.com

[8] L. Castañeda, J. Muñoz and J. Ancheyta, "Combined Process Schemes for Upgrading of Heavy Petroleum," Fuel, Vol. 100, 2012, pp. 110-127. http://dx.doi.org/10.1016/j.fuel.2012.02.022

[9] R. Martínez-Palou, et al., "Transportation of Heavy and Extra-Heavy Crude Oil by Pipeline: A Review,” Journal of Petroleum Science and Engineering, Vol. 75, No. 3-4, 2001, pp. 274-282. http://dx.doi.org/10.1016/j.petrol.2010.11.020

[10] M. Rana, et al., "A Review of Recent Advances on Process Technologies for Upgrading of Heavy Oils and Residua,” Fuel, Vol. 86, No. 9, 2007, pp. 1216-1231. http://dx.doi.org/10.1016/j.fuel.2006.08.004

[11] J. Le Page, S. Chatila and M. Davidson, "Residue and Heavy Oil Processing,” Technip, Paris, 1992.

[12] M. Gray, "Upgrading Petroleum Residues and Heavy Oils,” Marcel-Dekker, 1994.

[13] J. Speight, "Chapter 5: Thermal Cracking The Refinery of the Future, and Hydrotreating (HDT),” 2011, pp. 147180.

[14] R. Radmanesh, E. Chan and M. Gray, "Modeling of Mass Transfer and Thermal Cracking during the Coking of Athabasca Residues,” Chemical Engineering Science, Vol. 63, No. 6, pp. 1683-1691. http://dx.doi.org/10.1016/j.ces.2007.11.019

[15] J. Gearhart and L. Garwin, "Resid-Extraction Process Offers Flexibility,” Oil \& Gas Journal, Vol. 74, No. 24, 1976, pp. 63-66.

[16] R. Newcomer and R. Soltau, "Heavy Oil Extraction ups FCC Feed at First Three-Stage Grass Roots ROSE Unit, in Kansas," Oil \& Gas Journal, Vol. 80, No. 26, 1982, pp. 108-110.

[17] J. S. Plotkin, "Exploiting Unconventional Heavy Oils," PTQ Q1, 2007, pp. 65-67.

[18] J. Elliott and M. McGrath, "Cost Effective Conversion of Heavy Residues,” March, 2009, pp. 51-58.

[19] "Liquid-Liquid in Continuous Extraction Pilot Plant," Gaceta 448 del 9 del Julio, 1997, p. 216.

[20] Patent Colombian, "Visbreaking Pilot Plant,” Gaceta 444 del 7 de Mayo, 1997, p. 200.

[21] J. A. Carrillo, J. Cáceres, G. Vela and H. Bueno, "Solventes de Desasfaltado,” $C T \& F$, Vol. 1, No. 2, 1996, pp. 67-76.

[22] J. A. Carrillo and F. Pantoja, "Evaluación de Fondos de vacÍo en la Viscorreducción,” Ingeniería Química, Mayo. 1996, pp. 97-103.

[23] J. A. Carrillo, H. J. Picón, L. G. Garzón and L. M. Corredor, "Delayed Coking: Castilla and Jazmín Crude oils," ACS National Meeting, Fuel Chemistry, Boston, 23 August 2007. 